\title{
CARACTERIZAÇAO DOS TANINOS DA AROEIRA-PRETA (Myracrodruon urundeuva) ${ }^{1}$
}

Carla Regina Amorim dos Anjos Queiroz ${ }^{2}$, Sérgio Antônio Lemos de Morais ${ }^{3}$ e Evandro Afonso do Nascimento ${ }^{3}$

\begin{abstract}
RESUMO - Visando contribuir para a caracterização química de uma madeira nobre nativa e em extinção no Brasil, no presente trabalho estão apresentados os estudos de identificação e quantificação dos taninos da aroeirapreta (Myracrodruon urundeuva), uma espécie da família Anacardiaceae. Este estudo foi conduzido com base nos extratos acetona-água (AA) e metanol-água (MA), em que foram determinados os teores de fenóis totais e proantocianidinas. O teor de fenóis totais foi determinado pelo método Folin-Ciocalteau e pelo método azul-daprússia modificado. Os valores encontrados para os métodos AA foram 19,1 e 24,7\% e para MA, 20,2 e 22,8\%, respectivamente. $\mathrm{O}$ teor de proantocianidinas foi determinado pelo método da vanilina, tendo alcançado no extrato AA 2,7\% e no MA 16,7\%. Não foram constatadas as presenças de antocianidinas nem de apigedinidinas, podendo haver 3-deoxi-proantocianidinas do tipo luteolinidinas. Por meio da cromatografia líquida de alta eficiência (CLAE), foram identificados a fisetina e os ácidos gálico e elágico. Os resultados mostram que a aroeira-preta contém uma elevada quantidade de taninos, que podem contribuir para sua resistência natural à degradação.
\end{abstract}

Palavras-chave: Aroeira-preta, polifenóis e taninos.

\section{CHARACTERIZATION OF AROEIRA-PRETA (Myracrodruon urundeuva) WOOD TANNINS}

\begin{abstract}
This work presents a study on tannins from aroeira-preta (Myracrodruon urundeuva), based on acetone-water (AA) and methanol-water (MA) extracts, in which the contents of total phenols and proanthocyanidins were determined. The total phenols were determined by the Folin-Ciocalteau method and the modified Prussian Blue method. The contents obtained for AA were 19.1 and $24.7 \%$ and for $M A, 20.2$ and $22.8 \%$, respectively by the Folin-Ciocalteau method and the modified Prussian Blue method. The proanthocyanidin contents were determined by the vanillin method, obtaining $2.7 \%$ in extract $A A$ and $16.7 \%$ in extract $M A$. No evidence for the presence of antocyanidins and apigedinidins was found, but 3-deoxi-proantocyanidins of the luteolinidin type may be present in the extracts. Fisetin, gallic acid and ellagic acid were detected through high performance liquid chromatography (HPLC). These results show that Myracrodruon urundeuva wood contains a great amount of tannins, which can contribute to its natural durability.
\end{abstract}

Key words: $\quad$ Aroeira-preta, polyphenols, tannin.

\section{INTRODUÇÃO}

$\mathrm{O}$ termo aroeira tem sido usado para designar plantas classificadas em três gêneros da família Anacardiaceae: Lithraea, Schinus e Astronium. A aroeira-preta é a Miracrodruon urundeuva Allemão, que possui os sinônimos Astronium juglandifolium Griseb. e Astronium urundeuva Engl. (Santos, 1987; Moraes \& Freitas, 1997). Considerada madeira de lei, ela é muito densa, dura, elástica, resistente a cupins, recebe excelente polimento e, quando seca, é de difícil trabalhabilidade (Santos, 1987; Rizzini, 1995; Moraes \& Freitas, 1997).

1 Recebido para publicação em 15.8.2001.

Aceito para publicação em 20.6.2002.

2 Bolsista da FAPEMIG na área de Química da Madeira do Instituto de Química da Universidade Federal de Uberlândia UFU, Caixa Postal 593, 38400-902 Uberlândia-MG; ${ }^{3}$ Professores do Instituto de Química da UFU, <salemos@ufu.br>. 
Estudos realizados pelo Instituto de Pesquisas Tecnológicas (IPT) indicam que um pedaço de aroeirapreta do tamanho de uma caixa de fósforos suporta 6 toneladas de carga, sem se deformar. A característica de durabilidade é encontrada em apenas 1 a $5 \%$ das madeiras e apenas menos de $1 \%$ delas são muito duráveis. De acordo com testes realizados pelo IPT, a aroeira-preta foi classificada como muito durável e está incluída no grupo das madeiras chamadas imputrescíveis (Mainieri \& Chimelo, 1989; Braga, 1990).

Além das propriedades mecânicas que formam uma barreira física de proteção, existe também uma barreira química, formada por substâncias produzidas pela própria árvore, denominadas de extrativos, que possuem efeitos fungicida e inseticida. Essas substâncias se formam principalmente no processo de transformação do alburno em cerne (Braga, 1990).

O termo tanino foi o nome dado à infusão de cascas de árvores como o carvalho e a castanheira, na qual as peles de animais eram tratadas para obtenção de couros maleáveis e de grande durabilidade. Os taninos foram inicialmente identificados pelo seu sabor adstringente e pela sua capacidade de precipitar proteínas solúveis. Eles são encontrados em muitas plantas usadas pelo homem na forma de ervas medicinais, na alimentação e na fabricação de bebidas. Nas plantas, os taninos podem ser encontrados em raízes, flores, frutos, folhas, cascas e na madeira. Eles contribuem para o sabor adstringente em comidas e bebidas, como aquele sentido ao se consumir vinhos tintos, chás e frutas verdes. Alguns investigadores provaram que os taninos servem para proteger as plantas contra os herbívoros e as doenças patogênicas (Bernays et al., 1989; Harbone et al., 1991).

Uma definição mais precisa e muita empregada atualmente para taninos foi dada por Haslam (1989), segundo qual o termo designa os metabólitos secundários de natureza polifenólica extraídos de plantas, taninos vegetais, que foram classificados em dois grupos: as proantocianidinas, que são os taninos condensados, responsáveis pelas características normalmente atribuídas a estas substâncias, como adstringência, precipitação de proteínas etc., e os taninos hidrolisáveis, que são ésteres do ácido gálico e seus dímeros (ácido digálico ou hexaidroxidifênico e elágico) com monossacarídeos, principalmente a glucose.

Normalmente, os taninos hidrolisáveis são divididos em galotaninos, que produzem ácido gálico após hidrólise, e em elagitaninos, que produzem ácido elágico após hidrólise (Nascimento \& Morais, 1996; Garro et al., 1997). Estes taninos não são muito comuns em madeiras, quando comparados aos taninos condensados. Na Figura 1 estão apresentados exemplos de galotaninos e elagitaninos.

Os taninos condensados perfazem, aproximadamente, a metade da matéria seca da casca de muitas árvores. Eles constituem a segunda fonte de polifenóis do reino vegetal, perdendo apenas para a lignina. Além de serem potentes antioxidantes, possuem larga aplicação na complexação com proteínas, sendo por isto muito empregados na indústria de couros (Hagerman et al., 1997; Argyropoulos, 1999).

A estrutura dos taninos condensados é formada pela ligação de uma série de monômeros de unidades flavan3-ol, ou por um derivado desta. Esta ligação ocorre normalmente entre os carbonos 4 de uma estrutura e 8 da outra. Variações podem ocorrer por diferentes números de monômeros ligados, pela posição de ocorrência das ligações, pelo padrão de oxigenação nos anéis A e B da unidade flavan-3-ol e pela estereoquímica dos substituintes do anel C. Na Figura 2, demonstra-se a estrutura de um tanino condensado muito comum, a procianidina.

A análise dos taninos de madeira envolve sua extração, seguida de ensaios para determinação de seus constituintes. A extração se dá, basicamente, pela solubilização desses constituintes em diferentes solventes, em que se destacam as misturas: acetona:água e metanol:água (Cork \& Krockenberger, 1991; Conde et al., 1997; Lu \& Foo, 1997; Hagerman et al., 1977; Hagerman, 1998).

Apesar da importância da madeira de aroeira-preta, não foram encontrados, na literatura, estudos químicos a respeito de sua lignina, extrativos polifenólicos (taninos) e da possível ligação da resistência natural à degradação com sua constituição química. Assim, o objetivo deste trabalho foi identificar e quantificar os taninos da aroeirapreta (Myracrodruon urundeuva).

\section{MATERIAL E MÉTODOS}

\subsection{Preparação da Amostra de Aroeira-Preta}

Um tronco de aroeira-preta procedente do cerrado do Triângulo Mineiro, de 30 anos de idade, foi seco ao ar livre durante um ano. Decorrido esse período, ele foi descascado, cortado em discos, moído em moinho de bolas e passado em peneira de 40 meshes. 


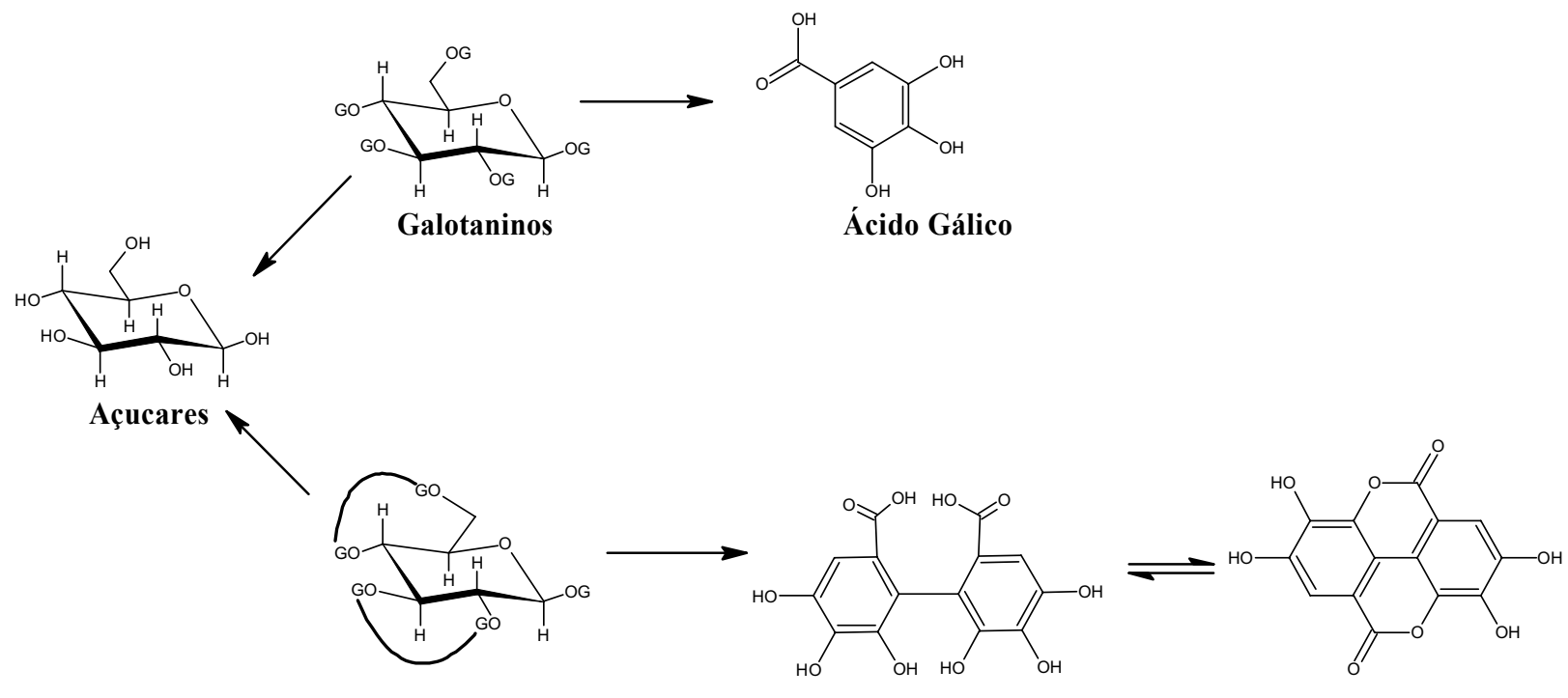<smiles>C=CC(=O)c1cc(O)c(O)c(O)c1</smiles>

Elagitaninos

Ácido

Heaxaidroxidifênico

Figura 1 - Taninos hidrolisáveis.

Figure 1 - Hydrolyzable tannins.

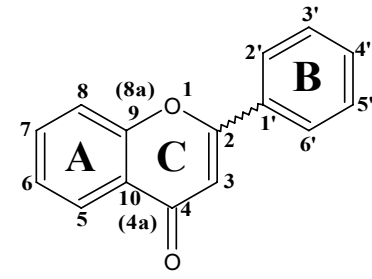

Flavonóide (a)

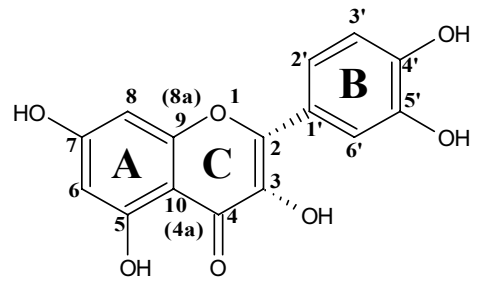

Flavan-3-ol (b)

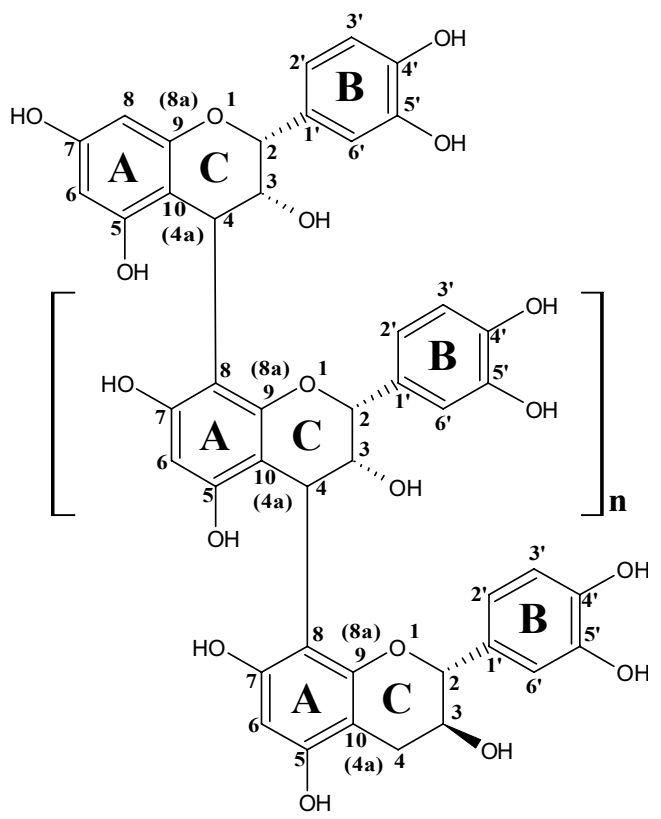

Procianidina (c)

Figura 2 - Fórmulas estruturais: a) um flavanóide genérico, b) flavan-3-ol e c) procianidina (tanino condensado). Figure 2 - Structural formulas: a) generic flavanoid, b) flavan-3-ol, c) procyanidin (condensed tannin). 


\subsection{Obtenção dos Extrativos Polifenólicos}

\subsubsection{Metanol-Água 8:2 (v/v)}

Foram colocados em um béquer $10,0 \mathrm{~g}$ da madeira moída de $A$. urundeuva de granulometria $\leq 40$ meshes e adicionaram-se $300 \mathrm{ml}$ da mistura metanol-água 4:1 $(\mathrm{v} / \mathrm{v})$. O material foi mantido por 24 horas em ambiente escuro, sob temperatura ambiente e agitação constante. Depois de decorrido este período de tempo, o material foi filtrado com funil de Buchnner e papel-filtro. Do filtrado obtido, retirou-se uma alíquota de $10 \mathrm{ml}$. A alíquota foi seca durante 18 horas em estufa a $103 \pm 2{ }^{\circ} \mathrm{C}$, para cálculo de rendimento do extrato bruto. $\mathrm{O}$ restante do filtrado foi evaporado sob pressão reduzida de $40 \mathrm{mmHg}$, à temperatura de $40^{\circ} \mathrm{C}$, para eliminar o metanol. Os ensaios foram realizados com esta amostra (MA) e com sua duplicata, obtida de forma semelhante (MA1).

\section{Acetona-Água 7:3 (v/v)}

Foram colocados em um béquer $10,0 \mathrm{~g}$ de madeira moída de $A$. urundeuva de granulometria $\leq 40$ meshes e adicionaram-se $300 \mathrm{ml}$ da mistura acetona-água 7:3 $(\mathrm{v} / \mathrm{v})$. Os demais procedimentos foram semelhantes ao adotado para extração em metanol-água.

\subsection{Determinação do Teor de Fenóis Totais}

\subsubsection{Método do Azul-da-Prússia Modificado}

Em 0,10 ml de cada extrato bruto (AA e MA ), adicionaram-se $1,0 \mathrm{ml}$ de $\mathrm{K}_{3} \mathrm{Fe}(\mathrm{CN})_{6} 0,016 \mathrm{M}$ e $1,0 \mathrm{ml}$ de $\mathrm{FeCl}_{3}$ em $\mathrm{HCl} 0,1 \mathrm{~N}$. Agitou-se e manteve-se à temperatura ambiente por 15 minutos. Adicionaram-se $3,0 \mathrm{ml}$ de solução de ácido fosfórico $85 \%$ e deixou-se em repouso por 2 minutos. Acrescentaram-se 2,0 ml de goma arábica a $1 \%$ e registrou-se a absorvância da solução a $700 \mathrm{~nm}$, ao usar um branco como referência. Procedeu-se de forma semelhante com as soluções-padrão de ácido gálico $(1-50 \mu \mathrm{g} / \mathrm{ml})$.

\subsubsection{Método Folin-Ciocalteau}

Retirou-se $0,10 \mathrm{ml}$ de cada extrato bruto (AA e MA) e diluiu-se com água destilada para 50,0 ml. Retirou-se uma alíquota de $0,5 \mathrm{ml}$. À alíquota foram adicionados $2,5 \mathrm{ml}$ de uma solução aquosa do reagente de FolinCiocalteau a $10 \%$ e $2,0 \mathrm{ml}$ de carbonato de sódio a 7,5\%.
A mistura foi mantida por 5 minutos em banho-maria, a $50{ }^{\circ} \mathrm{C}$, e a absorvância a $760 \mathrm{~nm}$ foi registrada. Procedeuse de forma semelhante com as soluções-padrão de ácido gálico $(1-50 \mu \mathrm{g} / \mathrm{ml})$ e com o branco.

\subsection{Determinação de Proantocianidinas}

\subsubsection{Método da Vanilina}

Adicionou-se, em tubo de ensaio, $1,0 \mathrm{ml}$ de cada extrato bruto (MA e AA) e acrescentaram-se $2,0 \mathrm{ml}$ de solução de vanilina a 2\% em ácido sulfúrico a 70\% (2,0 g de vanilina diluída a $100 \mathrm{ml}$ com ácido sulfúrico $70 \%$ ). A mistura foi posta em banho de água a $20{ }^{\circ} \mathrm{C}$ por um período de 15 minutos. A leitura da absorvância a $500 \mathrm{~nm}$ foi registrada. $\mathrm{O}$ mesmo procedimento foi seguido para execução da curva de calibração, ao utilizar como padrão a catequina, em faixa de concentração de 2,5 a $40 \mu \mathrm{g} / \mathrm{ml}$.

\subsubsection{Método Butanol-Ácido}

Transferiu-se 0,5 $\mathrm{ml}$ de cada extrato bruto (MA e AA) e para um tubo de reação e adicionaram-se $1,0 \mathrm{ml}$ de n-butanol-ácido clorídrico concentrado 95:5 (v/v) e $40 \mu \mathrm{L}$ de reagente férrico a $2 \%\left(\mathrm{NH}_{4} \mathrm{Fe}\left(\mathrm{SO}_{4}\right)_{2} \cdot 12 \mathrm{H}_{2} \mathrm{O}\right.$ em HCl 2,0 M). Fechou-se o tubo de reação e este foi mantido em estufa a $95 \pm 2{ }^{\circ} \mathrm{C}$ por 1 hora. Após a reação, a absorvância a $550 \mathrm{~nm}$ foi registrada.

\subsection{Determinação de 3-Deoxi-Proantocianidinas}

Em tubo de ensaio foram misturados $0,1 \mathrm{ml} \mathrm{de}$ amostra (AA ou MA), $10 \mathrm{ml}$ de butanol-ácido clorídrico concentrado 95:5 (v/v) e 0,2 $\mathrm{ml}$ de sulfato férrico amoniacal a $2 \%$ em $\mathrm{HCl} 2,0 \mathrm{~N}$. O branco foi constituído de uma mistura de $15 \mathrm{ml}$ de ácido acético $0,1 \mathrm{~N}, 15 \mathrm{ml}$ de metanol e $70 \mathrm{ml}$ de n-butanol. A absorvância de cada amostra com butanol-ácido foi comparada à absorvância do branco.

\subsection{Cromatografia Líquida de Alta Eficiência (CLAE)}

Foi utilizado um cromatógrafo Hewlett-Packard mod. $1050 \mathrm{M}$, com sistema de bombeio quartenário, injetor automático, detetor de fotodiodos mod. $1040 \mathrm{M}$ e estação de tratamentos de dados. A coluna empregada foi do tipo Hypersil ODS ( $200 \times 4$ mm diâmetro interno), de $5 \mu \mathrm{m}$ de diâmetro de partícula. A mistura de solventes 
empregada para eluição foi: X: $\mathrm{MeOH}: \mathrm{H}_{3} \mathrm{PO}_{4}(999: 1)$ e $\mathrm{Y}: \mathrm{H}_{2} \mathrm{O}: \mathrm{H}_{3} \mathrm{PO}_{4}(999: 1)$, com gradiente: $0 \mathrm{~min}-40 \mathrm{~min}$, $20 \%-100 \% \mathrm{X} ; 40 \mathrm{~min}-45 \mathrm{~min}, 100 \% \mathrm{X}$. A vazão foi de $1 \mathrm{ml} / \mathrm{min}$, a temperatura do forno foi de $30{ }^{\circ} \mathrm{C}$ e foram injetados $2,0 \mu \mathrm{l}$. O detetor foi programado a $270 \pm 15,325$ \pm 75 e $365 \pm 2 \mathrm{~nm}$. Os compostos foram identificados na biblioteca de compostos fenólicos e flavanóides existentes na estação de tratamentos de dados e em tempos de retenção.

\section{RESULTADOS E DISCUSSÃO}

O Quadro 1 apresenta os resultados obtidos com as extrações, tomadas em relação à madeira seca. Com estes dados, constata-se que para a $A$. urundeuva há diferença de 3,7\% no rendimento da extração entre as duas misturas de solventes.

Quadro 1 - Rendimentos médios dos extratos Table 1 - Average extract yield

\begin{tabular}{|l|c|}
\hline \multicolumn{1}{|c|}{ Extrato } & Rendimento (\%) \\
\hline (AA) Acetona-água 7:3 (v/v) & 22,4 \\
(MA) Metanol-água 4:1 (v/v) & 18,7 \\
\hline
\end{tabular}

A título de comparação, os rendimentos obtidos para os extratos acetona:água de duas espécies de Eucalyptus, outra madeira cultivada no cerrado e que se degrada facilmente, foram $E$. grandis W.Hill ex Maiden 7,8\% e E. uropylla S.T. Blake 12,2\% (Chang, 2000). O rendimento do extrato acetona:água obtido da aroeira-preta foi bastante superior ao das duas espécies de Eucalyptus. Os extratos metanol:água de algumas espécies de Eucalyptus cultivadas em outras regiões também apresentam baixo rendimento (Figura 3, adaptada de Conde et al., 1995, 1996, 1997).

O Quadro 2 apresenta os resultados da reta obtida na curva de calibração com ácido gálico para cada amostra, pelo método Folin-Ciocalteau. Este resultado indica uma variação de $6,1 \%$ entre um resultado e outro, sendo o extrato acetona-água o de maior rendimento para este ensaio.

Valores médios de fenóis totais de 3,3\% para o E. grandis e 4,1\% para o E. urophylla foram encontrados por Chang (2000). Estes resultados indicam que a madeira de $A$. urundeuva possui um teor de fenóis totais bem superior ao encontrado para as espécies de Eucalyptus estudadas.
O Quadro 3 apresenta os resultados ao utilizar a reta obtida na curva de calibração com ácido gálico para cada amostra pelo método azul-da-prússia modificado (Graham, 1992).

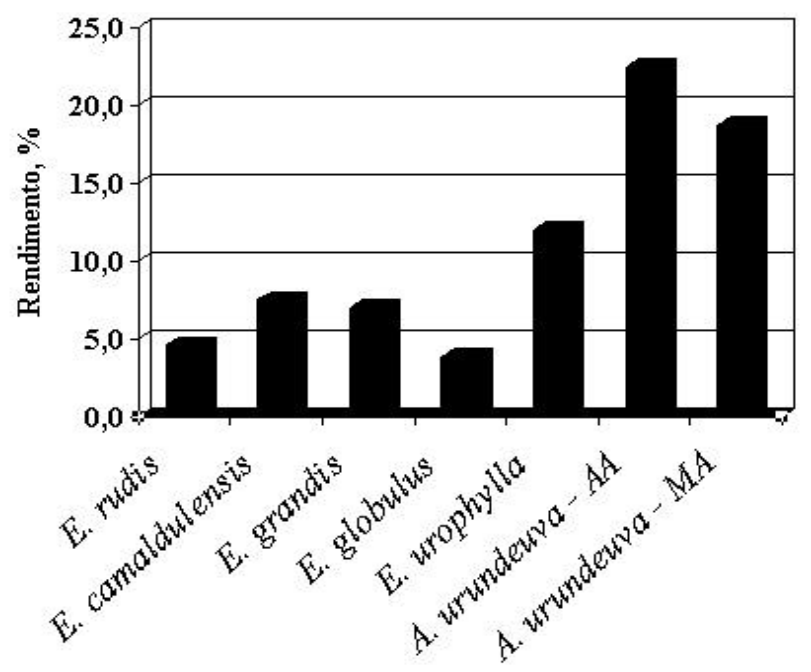

Figura 3 - Comparação do rendimento dos extratos acetona:água e metanol:água para as madeiras de aroeira-preta e algumas espécies Eucalyptus.

Figure 3-Comparison of methanol:water and acetone: water yield for aroeira-preta and Eucalyptus spp. wood.

Quadro 2 - Fenóis totais pelo método Folin-Ciocalteau em equivalentes de ácido gálico

Table 2 - Total phenol yields by the Folin-Ciocalteau method in gallic acid equivalents

\begin{tabular}{|l|c|c|}
\hline \multirow{2}{*}{ Amostra } & \multicolumn{2}{|c|}{ Rendimento } \\
\cline { 2 - 3 } & $\begin{array}{c}\text { mg em equivalentes de ácido } \\
\text { gálico/g madeira seca }\end{array}$ & \% do extrato bruto \\
\hline AA & 43,8 & 19,1 \\
MA & 37,7 & 20,2 \\
\hline
\end{tabular}

Quadro 3 - Fenóis totais obtidos pelo método azul-daprússia modificado, em equivalentes de ácido gálico

Table 3 - Total phenol yields by the modified Prussian Blue method in gallic acid equivalents

\begin{tabular}{|l|c|c|}
\hline \multirow{2}{*}{ Amostra } & \multicolumn{2}{|c|}{ Rendimento } \\
\cline { 2 - 3 } & $\begin{array}{c}\text { mg em equivalentes de ácido } \\
\text { gálico/g madeira seca }\end{array}$ & \% do extrato bruto \\
\hline AA & 55,4 & 24,7 \\
MA & 42,6 & 22,8 \\
\hline
\end{tabular}


Esse resultado indica que o ensaio para determinação de fenóis totais, pelo método do azul-da-prússia, produz maiores rendimentos do que o Folin-Ciocalteau, tanto em AA quanto em MA.

O Quadro 4 apresenta os resultados para o teor de proantocianidinas pelo método da vanilina, ao empregar a reta obtida na curva de calibração com catequina para cada amostra.

Quadro 4 - Rendimento de proantocianidinas obtido pelo método da vanilina, em equivalentes de catequina

Table 4 - Proanthocyanidin yield by the vanillin method in catechin equivalents

\begin{tabular}{|l|c|c|}
\hline \multirow{2}{*}{ Amostra } & \multicolumn{2}{|c|}{ Rendimento } \\
\cline { 2 - 3 } & $\begin{array}{c}\text { mg em equivalentes de } \\
\text { catequina/g madeira a.s }\end{array}$ & \% do extrato bruto \\
\hline AA & 6,1 & 2,7 \\
MA & 31,2 & 16,7 \\
\hline
\end{tabular}

Ao contrário dos valores obtidos para fenóis totais, o teor de proantocianidinas foi maior no extrato metanolaquoso. Esta diferença foi significativa. Os resultados permitem afirmar que, para esta espécie de madeira, as proantocianidinas são preferencialmente extraídas em metanol-água.

A degradação oxidativa das proantocianidinas, que as transforma em antocianidinas, ocorre por aquecimento do extrato (AA e MA) em butanol-ácido. A curva obtida por esse método é bifásica e consiste de duas retas (Stafford \& Lester, 1980), o que resulta em problema, pois a relação de Lambert-Beer entre a absorvância e a concentração de antocianidinas apenas pode ser aplicada em baixas faixas de concentração $(<0,2)$. As amostras brutas (AA e MA) tiveram absorvância muito alta $(>2,5)$ no comprimento de onda $550 \mathrm{~nm}$, que é característico das antocianidinas resultantes da reação. Foram feitas diluições que levaram ao desaparecimento do pico em $550 \mathrm{~nm}$. Neste caso, não foi possível a quantificação das proantocianidinas por meio desse experimento (Queiroz, 2001).

A comprovação da existência de 3-deoxi-proantocianidinas é feita basicamente por comparação das amostras com o branco em relação à amostra com butanol-ácido. Para o comprimento de onda $485 \mathrm{~nm}$, as diferenças entre as amostras com o branco e com butanolácido não foram significativas. Estes resultados indicam que nessas amostras não houve presença de apigedinidinas. Já em $495 \mathrm{~nm}$, a diferença de absorvância das amostras foi maior, indicando que há 3-deoxi-proantocianidinas do tipo luteolinidinas (Queiroz, 2001).

Por intermédio da CLAE foram estudadas as frações solúveis em água e em éter etílico do extrato metanolágua da $A$. urundeuva. No extrato aquoso, depois da extração com éter, foram constatados um pico referente ao ácido gálico e uma banda larga composta por diferentes tipos de proantocianidinas (Nascimento \& Morais, 1996; Morais et al.,1999).

A Figura 4 mostra o cromatograma dos componentes extraídos do extrato aquoso com éter. O principal componente apresentado é a fisetina (5). Além deste composto, foram identificados os ácidos gálico e elágico (1 e 3 , respectivamente) e as concentrações menores de compostos que apresentam espectros de UV característicos de flavanonas (2), flavanóis (7) e elagitaninos (6).

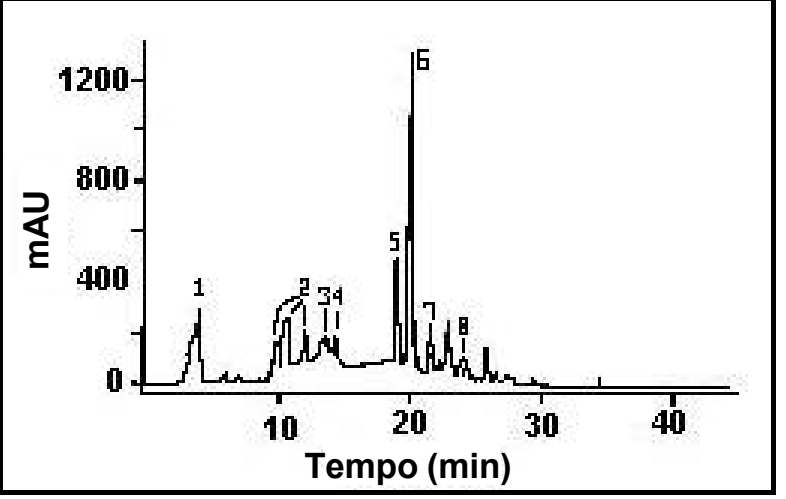

Figura 4 - Cromatograma dos componentes extraídos do extrato aquoso com éter.

Figure 4-HPLC chromatogram of the ether soluble components extracted from the aqueous extract.

A presença de fisetina no extrato etéreo, juntamente com outros dados da literatura, indica que os taninos da aroeira-preta são do tipo profisetidinas, conforme citado por Morais et al. (1999).

\section{CONCLUSÕES}

- Para a madeira de A. urundeuva, a acetona foi mais eficaz para dissolver os extrativos do que o metanol e o teor de fenóis totais dessa espécie de madeira foi bem superior ao encontrado para as espécies de Eucalyptus estudadas. 
- A determinação de fenóis totais, pelo método do azulda-prússia, produziu maiores rendimentos do que o Folin-Ciocalteau, tanto em AA quanto em MA.

- Para esta espécie de madeira, as proantocianidinas foram preferencialmente extraídas em metanol-água.

- Por meio do experimento em butanol-ácido, averiguouse que as 3-deoxi-proantocianidinas são do tipo luteolinidinas e que não há apigedinidinas. Não foi possível a quantificação das proantocianidinas por meio deste método.

- A presença de fisetina no extrato etéreo indicou que os taninos da aroeira-preta são do tipo profisetidinas.

- A elevada quantidade de extrativos fenólicos classifica essa madeira como muito rica em metabólitos secundários, que podem ou não estar associados com a lignina e que, provavelmente, são os principais responsáveis pela larga resistência natural da Myracrodruon urundeuva à degradação química e biológica.

\section{AGRADECIMENTOS}

Os autores desejam agradecer à Fundação de Apoio à Pesquisa de Minas Gerais - FAPEMIG, pela bolsa de mestrado concedida; ao Instituto Nacional de Investigaciones Agrarias I.N.I.A - Madrid - Espanha, pelos cromatogramas de CLAE, e ao Instituto de Química da Universidade Federal de Uberlândia - IQUFU, pelo suporte durante as experiências.

\section{REFERÊNCIAS BIBLIOGRÁFICAS}

ARGYROPOULOS, D. S. Advances in lignocellulosics characterization. Atlanta: TAPPI Press, 1999. p. 157-180.

BERNAYS, E. A.; DRIVER, G. C.; BILGENER, M. Herbivores and plant tannins. Advana Ecology Research, v. 19, p. 263-302, 1989.

BRAGA, R. Plantas do Nordeste: especialmente do Ceará. 4.ed. Natal: Escola Superior de Agricultura de Mossoró, 1960. $315 \mathrm{p}$.

CHANG, R. Análise dos compostos fenólicos da madeira do $E$. grandis e do E. urophylla do Triângulo Mineiro. Uberlândia: Universidade Federal de Uberlândia, 2000. 105 p. Dissertação (Mestrado em Química) - Universidade Federal de Uberlândia, 2000.

CONDE, E. et al. Polyphenolic composition of wood extracts from Eucalyptus camaldulensis, globulus and rudis. Holzforschung, v. 49, n. 5, p. 411-417, 1995.
CONDE, E. et al. Polyphenolic composition of bark extracts from Eucalyptus camaldulensis, globulus and rudis. Holz als Roh und Werkstoff, v. 54, n. 3, p. 175-181, 1996.

CONDE, E.; CADAHÍA, E.; GARCÍA-VALLEJO, M. C. High-pressure liquid chromatographic analysis of polyphenols in leaves of Eucalyptus camaldulensis, globulus and rudis: Proanthocyanidins, ellagitannins and flavonol glycosides. Phytochemical Análisis, v. 8, n. 2, p. 78-83, 1997.

CORK, S. J.; KROCKENBERGER, K. Methods and pitfalls of extracting condensed tannins and other phenolics from plants - insights from investigations on eucalyptus leaves. Journal of Chemical Ecology, v. 17, n. 1, p. 123-134, 1991.

GALVEZ, J. M. G.; RIEDL, B.; CONNER, A. H. Analytical studies on tara tannins. Holzforschung, v. 51, n. 3, p. 235-243, 1997.

GRAHAM, H. D. Stabilization of the Prussian Blue color in the determination of polyphenols. Journal of Agricuture Food Chemistry, v. 40, n. 5, p. 801-805, 1992.

HAGERMAN, A. E.; ZHAO, Y.; JOHNSON, S. E.; SHAHADI, F. Methods for determination of condensed and hydrolyzable tannins. Acs Sym Ser, v. 662, p. 209-222, 1997.

HAGERMAN, A. E. Extraction of tannin from fresh and preserved leaves. Journal of Chemical Ecology, v. 14, n. 2, p. 453-461, 1988.

HARBOnE, J. B.; PALO, R. T.; ROBBINS, C. T. Plant defenses against mammalian herbivore. $\mathrm{C} R \mathrm{C}$ Press LLC, 1991. 192 p.

HASLAM, E. Plant polyphenols. Cambridge: Cambridge University Press, 1989. 230 p.

LU, Y.; FOO, L. Y. Identification and quantification of major polyphenols in apple pomace. Food Chemistry, v. 59, n.2, p. 187-194, 1997.

MAINIERI, C.; CHIMELO, J. P. Fichas características de madeiras brasileiras. São Paulo: IPT, 1989. 49p.

MORAES, M. L. T.; FREITAS, M. L. M. Resumos Embrapa - CPAO/Flora Sul. Dourados-MS: 1997. p. 9. (Boletins Informativos)

MORAIS, S. A. L.; NASCIMENTO, E. A.; QUEIROZ, C. R. A. A. Studies on polyphenols of Myracrodruon urundeuva wood. Journal of the Brazilian Chemical Society, v. 10, n. 6, p. 447-452, 1999.

R. Árvore, Viçosa-MG, v.26, n.4, p.485-492, 2002 
NASCIMENTO, E. A.; MORAIS, S. A. L. Polifenóis da madeira de Eucalyptus grandis. Parte 1: análise por espectroscopia e cromatografia líquida. Ciência \& Engenharia, v. 5, n. 2, p. 13-18, 1996.

QUEIROZ, C. R. A. A. Análise da lignina e dos polifenóis da aroeira-preta (Myracrodruon urundeuva). Uberlândia: Universidade Federal de Uberlândia 2001. 142 p.

Dissertação (Mestrado em Química) - Universidade Federal de Uberlândia, 2001.
RIZZINI, C. T. Árvores e madeiras úteis do Brasil manual de dendrologia brasileira. 2.ed. São Paulo: Edgard Blucher, 1995. $296 \mathrm{p}$.

SANTOS, E. Nossas madeiras. Belo Horizonte: Itatiaia, 1987. $316 \mathrm{p}$.

STAFFORD, H. A.; LESTER, H. H. Procyanidins (condensed tannins) in green cell-suspension cultures of douglas-fir compared with those in strawberry and avocado leaves by means of c18-reversed-phase chromatography.

Plant Physiology, v. 66, n. 6, p. 1085-1090, 1980. 